sulphasalazine was discontinued. The ulcerative colitis deteriorated and was not controlled by prednisolone given orally and by enema. The develop ment of toxic megacolon in November 1978 necessitated a colectomy. Two weeks after this he was inadvertently given co-trimoxazole for a urinary tract infection. Three days later this was followed by a rapidly spreading erythematous rash, which soon became universal and scaly. His general condition deteriorated and the eruption showed no response to progressive increases in prednisolon therapy (maximum $120 \mathrm{mg}$ daily). Eight weeks after co-trimoxazole had been discontinued a skin biopsy was taken and showed parakeratosis, mild papillomatosis, and permeation of the epidermis b neutrophils.

A diagnosis of erythrodermic psoriasis was made and methotrexate was begun orally once weekly. The erythroderma began to resolve after the second dose, and four weeks from the onset of methotrexate therapy abnormal findings in the skin were limited to well-defined silvery, scaled plaques over the elbows, on the scalp, and on the hands and feet As the psoriasis came under control, the dose of prednisolone was gradually reduced and is currently at $4 \mathrm{mg}$ daily.

This case may represent an example of the Koebner phenomenon, the psoriasis having been triggered by a sulphonamide drug eruption. The diagnosis of psoriasis was delayed by the asence of any previous history, the clearcut relationship of the onset of the rash to sulphonamide ingestion, and the clinically non-specific nature of the erythrodermic form of the disease.

Cameron KenNedy

I M LEIGH

STEPHEN GOLD

Skin Department,

St George's Hospital,

\section{Prediction of gall-stone pancreatitis by computer}

SIR, - I read with interest the article "The prediction of gall-stone pancreatitis" by $\mathrm{Mr}$ D F Graham and Dr Frances J Wyllie (24 February, p 515), which highlighted some significant distinguishing features between acute pancreatitis of gall-stone aetiology and other causes. It is important to stress, however, that if a predictive index is to be used it is essential that the scoring system is based on data from the local population and that the data are current.

There were 57 admissions for proved acute pancreatitis to this Veterans Administration hospital over the last five years, of which 46 were first-time admissions and not for acute postoperative pancreatitis. Thirty-four case records were available for study and the aetiological factors were as follows: alcohol 15; gall stones 11; others 8.

With regard to the 10 significant differences identified by the authors between the two groupsgall stones or no gall stones-the following differences were found here:

\begin{tabular}{|c|c|c|}
\hline Symptoms and signs & $\begin{array}{l}\text { No stones } \\
\text { No }(\%)\end{array}$ & $\begin{array}{l}\text { Stones } \\
\text { No }(\%)\end{array}$ \\
\hline $\begin{array}{l}\text { Pain } \\
\text { Onset general ... } \\
\text { Present, right upper quadrant } \\
\text { Present, generalised } \quad . .\end{array}$ & $\begin{array}{l}16(70) \\
\therefore \quad 3(13) \\
\therefore \quad 20(87)\end{array}$ & $\begin{array}{l}8(73) \\
2(18) \\
8(73)\end{array}$ \\
\hline $\begin{array}{l}\text { faundice } \\
\text { History of jaundice } \\
\text { History of dark urine } \\
\text { Jaundiced clinically }\end{array}$ & $\begin{array}{ll}1 & (4) \\
1 & (4) \\
1 & (4)\end{array}$ & $\begin{array}{ll}1 & (9) \\
1 & (9) \\
1 & (9)\end{array}$ \\
\hline $\begin{array}{l}\text { Tenderness } \\
\text { Right upper quadrant } \ldots \\
\text { Generalised } \ldots \\
\text { Rebound tenderness } \\
\text { Murphy's test positive } \ldots\end{array}$ & $\begin{array}{lr}. & 7(30) \\
\therefore & 18(78) \\
\therefore & 5(22) \\
. & 0(0)\end{array}$ & $\begin{array}{l}4(36) \\
8(73) \\
0 \quad(0) \\
1 \quad(9)\end{array}$ \\
\hline
\end{tabular}

Thus, while it may be that in a population where the predominant aetiological factor is gall-stone disease, these features will be discriminant; it is clear that in this population they will not. It is possible that the increased incidence of pain and tenderness predominantly in the right upper quadrant in those without gall stones is related to the noted tender hepatomegaly in the acute alcoholic patient. This brief examination of patients seen here in a hospital system that deals with a high incidence of alcohol-related problems shows that discriminant features are no uniform for any disease. Further, as there is evidence that the aetiological pattern in acute pancreatitis is changing in the United Kingdom, ${ }^{1}$ these authors must be prepared to change their data base if they wish to continue with this in their programme-which, from personal experience, is a good diagnostic teaching aid.

Harry $S$ Truman Memorial

Veterans Hospital

1 Imrie, C W, and Whyte, A S, British fournal of Surgery, 1975, 62, 490.

\section{Bextasol and aphthous ulcers}

SIR,-Further to Dr Marianne Ganderton's letter (5 May, p 1216), may I too suggest a new use for aerosol inhalers, which may appeal to others.

I have found Bextasol Inhaler (Betamethasone Aerosol Inhalation, $B N F$ ) particularly useful in the management of aphthous ulcers, both personally and in a limited study. Usually these ulcers resolve spontaneously, of course; but while present they can often be quite troublesome. I have found that a puff of Bextasol Inhaler directed locally on to the ulcer site once or twice daily, for as long as required (rarely more than a day or so), both reduces pain and promotes early resolution. Each puff of Bextasol Inhaler contains only $100 \mu \mathrm{g}$ of betamethasone valerate, a steroid which has particularly high topical activitycompared, for example, with Hydrocortisone (Corlan) pellets, which contain $2.5 \mathrm{mg}$ of steroid and can be uncomfortable to retain in position.

In the presence of concurrent oral infection such as Candida albicans, when steroids would be contraindicated, a simple, soothing gel such as Bonjela is probably most useful.

Nicholas FisheR

Accident and Emergency Department,

Torbay Hospital

\section{Hepatotoxicity of erythromycin derivatives}

SIR,-In their recent article on drug-induced liver disease (14 April, p 992) Drs P W N Keeling and $\mathrm{R} \mathrm{P} \mathrm{H}$ Thompson wrote that "one, and only one, ester of erythromycin, the estolate, produces cholestasis, and so the reaction must be linked to the side chain rather than to the antibiotic itself."

Erythromycin estolate may not be the only villain of the erythromycin family. ${ }^{1} \mathrm{We}$ have seen a patient in whom severe abdominal pains, cholestatic jaundice, and eosinophilia occurred after the administration of erythromycin propionate; it subsided when the drug administration was interrupted and recurred when it was resumed. ${ }^{1}$ In another patient hepatitis followed the administration of erythromycin estolate and recurred after that of erythromycin propionate. ${ }^{2}$ In still another patient, hepatitis occurred after the administration of erythromycin ethylsuccinate. ${ }^{3}$ Experimentally, erythromycin and several of its derivatives have been shown to be cytotoxic to Chang human liver cells ${ }^{4}$ and cholestatic in the isolated perfused rat liver. ${ }^{5}$ These observations suggest that not only erythromycin estolate but also other erythromycin derivatives are hepatotoxic and that the reaction may be linked to the antibiotic itself rather than to the side chain.

Clearly, it is unfair to lay all the blame upon the estolate: his propionate and ethylsuccinate brothers are scoundrels too.

D Pessayre

J P Benhamou

Unité de Recherches de Physiopathologie

Hépatique,

2118 Clichy, France

Pessayre, D, et al, Archives Francaises des Maladies de l'Appareil Digestif, 1976, 65, 405

Tolman, K G, et al, Annals of Internal Medicine, 1974

81, 58.
Klatskin, G, in Diseases of the Liver, vol IV, ed L Schiff, p 604. Philadelphia, Lippincott, 1975.

Zimmerman, $\mathrm{H}$ J, et al, Proceedings of the Society for

Experimental Biology and Medicine, 1973, 144, 759.
Kendler, J, et al, Proceedings of the Society for Experimental Biology and Medicine, 1972, 139, 1272.

\section{The future of the Health Advisory Service}

SIR,-Dr A A Baker (7 April, p 967) writes that "Many of the problems in psychiatric and geriatric hospitals stem from a lack of understanding of a multidisciplinary approach to patient care." But with the increasing number of elderly patients being admitted to hospital into surgical, medical, and orthopaedic wards the Health Advisory Service ought not to limit itself purely to the elderly under the care of the psychiatrists and physicians in geriatric medicine. They should be enabled to visit all wards where significant numbers of elderly patients are admitted. Many of the general medical and orthopaedic wards lack the facilities for the comprehensive type of care that some of the elderly patients they have to admit require.

Nether Edge Hospital,

J $\mathbf{R} \operatorname{Cox}$

Sheffield S11 9EL

\section{Accident and emergency staff}

SIR,-During the past few years accident and emergency has established itself as a specialty in its own right and 10 senior registrars are already in post. I consider this to be a tremendous achievement, which will result in further improvement of the service provided by the accident and emergency departments in this country. The credit for the present state of affairs must be given to those of our colleagues who fought for this specialty to be given recognition and won against all odds. The Casualty Surgeons' Association has flourished over the years and the ambitious hopes of a handful of accident and emergency surgeons have become a reality. One of the founder members of this association is $\mathrm{Mr}$ John Collins, who is now its president.

Despite the progress there still remains the problem of the injustice to a group of medical practitioners who are still running accident and emergency departments but who have not yet been given the recognition of con- 
sultant status. The irony of the situation is that we hear repeatedly that there is lack of trained doctors suitable for consultant appointments and that no more consultant posts should be advertised for the time being. This implies that none of the medical assistants in accident and emergency currently in post is considered suitable for a consultant appointment. The question is who took that decision I have a strong suspicion that this policy is propagated by consultants in other specialties who are anxious to keep control of the accident and emergency departments. I happen to know personally a number of medical assistants who are excellent doctors, and who in spite of the restrictions which their status imposes on them have been doing a marvellous job in many parts of this country.

I think it is time the profession shows more concern for the treatment which a group of our colleagues are suffering and whose status makes it difficult for them to argue their case. This should be a matter of concern for all of us. I am aware of the fact that time and time again articles have been written in the $B M A$ News Review and other publications, but so far nothing constructive has been done to solve this problem fairly, which I am sure is causing a lot of anxiety to a number of doctors and their families.

N PYRgos

Accident and Emergency Department,

Lincoln County Hospital,
Lincoln LN2 5 QY

\section{Isolated communities and their doctors}

SIR,-Ever since the Rural Practice Fund replaced the old milage scheme in 1963 there has been progressive loss of general practitioners serving isolated communities. The Rural Practice Fund was intended to benefit rural doctors, but evidence has amassed to show that the real benefit was to doctors practising in small towns serving country areas. Thus today it is not uncommon for patients living in country areas to have to travel 10 miles $(16 \mathrm{~km})$ or more to country town group practices.

The Rural Practice Fund was specifically designed "to compensate the doctor working in a scattered practice for his proportionately greater expenses and few patients."' But enlarging the qualifying radius disproportionately increased the area $\left(\pi r^{2}\right)$ in which units could not be claimed. There are few direct roads in the country and to visit patients living three miles apart often means a journey of ten miles. A single-handed doctor has to serve the whole area but semirural partnerships are able to divide up the area, with consequent improvement in efficiency. In fairness, we believe, a two-man partnership should have a four-mile radius without entitlement to any milage units, a three-man partnership a fivemile radius, and so on. Fewer units to distribute would mean more money for each unit.

There can be no doubt that the application of the rule for fringe-urban practices created an injustice. It subsidised partnerships to invade the countryside and encouraged the absorption of practices which had become nonviable because of the rule. The situation continues today, though there are now few isolated practices left to be absorbed.

The problems of the single-handed isolated country doctor were nicely described in 1975 by the chairman of the Rural Practices Com- mittee. Commenting on the trend to partnerships in the country areas he said, "Most of the single-handed [village] doctors left are unable to join partnerships for geographical reasons and so have difficulty in making rota arrangements. Locums are increasingly hard to find and in any case are expensive. So, often the single-handed doctor has to soldier on with inadequate off-duty, little or no holiday, and insufficient time for postgraduate study. A survey of isolated practices in 1977 confirmed these views, and the present position has been clearly described by Scott. ${ }^{3}$

Surely what is required is an independent inquiry into the distribution of the Rura Practice Fund. Since its inception in 1963 rural doctors have been worse off than they were before, relatively, and a good case can be made for saying that it has adversely affected rural communities. Indeed, recent public discussion has pointed to the value of the village doctor along with the post office and school in maintaining the communal life of small villages. If there is to be a new charter for general practice then the wrongs which have existed since 1963 must be corrected. The New Charter Working Party has suggested many sensible improvements for general practice as a whole. We welcome the recommendations concerning special locum arrangements for isolated practices and a new look at the "linking of some practices in rural areas," but consider that these alone cannot redress the balance.

Shebbear, Devon

Michael S HaLI

\section{North Leverton,}

North Leverton,
Retford, Nottinghamshire

Black Torrington, Devon

R FILER-COOPER

C G Elliot

East Hoathly

Nr Lewes, Sussex

1 British Medical Fournal, 1963, 1, 13

$1,108$. Scott, G, World Medicine, 1979, 14, (9), 42 . British Medical Association, Report of New Charter
Working Group. London, BMA, 1979.

\section{The new consultant contract}

SIR,-The new consultant contract embodies the new concept that private practice will be open to all practitioners. If the maximum schedule of 13 sessions were allocated then the practitioner would be able to carry out private practice. Only when 14 or 15 NHDs are worked would private practice be precluded. No doubt the CCHMS envisaged that most practitioners would opt for 11-13 NHDs so that further remuneration from the private sector would supplement the diminishing returns of the NHS salary. This seemed a fair compromise as the decision to opt in or out of private medicine would go and the division between full-timers and part-timers be removed.

The workings of the Health Services Board regarding the new contract has escaped many of those writing to the $B M F$. Consultants in some specialties-for example, radiology, radiotherapy, and pathology-require facilities available only in NHS hospitals. If during the time when statistics were collected by the Health Services Board no consultant in these specialties was part-time the facilities would not appear to have been used for private practice and would be revoked.

Revocation of facilities for use of private patients virtually precludes private practice in those specialties requiring NHS equipment A keystone of the new contract has now been removed by the Health Services Board. The division would still exist between the specialties which have a revocation order against them and those that do not. The holders of the old contract would not be vulnerable but new appointees would be virtually appointed as full-timers (on negotiated NHDs) as they would have no access to NHS equipment necessary for their private practice. I feel that this seriously erodes a fundamental concept of the new contract. A further ballot is now necessary after pricing so that remuneration can be agreed in the wake of the Health Services Board revocation proposals.

R M IBBotson

North Staffordshire Hospital Centre,

Stoke-on-Trent, Staffs

SIR,-Further to the letters of Dr D E B Powell (24 March, p 825) and Mr Russell Hopkins (14 April, p 1022) concerning recall fees, I agree with Mr Hopkins that it has been a scandal since the advent of the NHS that the surgical specialties have been imposed on in this way. However, the statement that "Pathologists make several thousand extra pounds a year for their medicolegal work carried out during normal working hours" requires qualification.

Some of my colleagues do in fact get away with this and good luck to them. However, there are others, particularly those attached to the Home Office, whose peculiarly skilled and difficult work takes place mainly out of working hours but who, none the less, feel it only right and proper to give up sessions if undertaking this or private work. Needless to say, many of these unhappy individuals find that the unique responsibilities of their appointment de facto bar them from NHS awards, while their natural-indeed essential-wide interests expose them to remorseless and relentless pursuit by the demarcation squads of the Royal Union of "Pathologists."

Compared with our whole-time colleagues, we are indeed amateurs in at least one sense of the word.

J G Benstead

NW Home Office Forensic Science

Laboratory and Department of Pathology,

Southport General Infirmary,
Southport, Lancs PR8 6PH

\section{Peripheral hospitals and the new career} structure

SIR,-I take Mr R T Booth's point (13 January, $p$ 128) about the importance of equating service and training posts, and so far as the Guy's regional obstetric and gynaecology programme is concerned I do not feel the balance is too uneven. If one concedes that each district should have a maternity unit within the complex of the district general hospital, there are in the South-east Thames Region three teaching hospitals and 13 district hospitals, making a ratio of $1: 4 \cdot 3$. The Guy's programme-contrived, I may say, with the full participation of my regional colleaguesinvolves Guy's and four regional hospitals 